\title{
Exploring the Relations in Relational Engagement: Addressing Barriers to Transformative Consumer Research
}

\begin{abstract}
Marketing academics are increasingly seeking societal impact from their work yet still encounter problems in creating and sustaining meaningful relationships with those whom their work seeks to help. We use an empirical investigation to identify and propose solutions to the key barriers that impede the initiation and development of impactful relationships between marketing academics and Social Impact Organizations (SIOs). The investigation entailed 20 interviews with SIOs and Knowledge Exchange (KE) professionals in the US, UK and France. The main barriers hindering relationships are differing perspectives on resources, goal misalignment and misconceptions about the other party. Potential solutions include: involving both parties in structured activities for initializing collaboration; planning resource investment in research; engaging with KE professionals to facilitate goal alignment and to broker communications; increasing academic visibility in SIO communities; using teaching as a springboard to develop collaborations; supporting SIO-led initiatives and finding creative ways to overcome time incongruity.
\end{abstract}

\section{Introduction}

The global research landscape is shifting, with greater recognition that academics must engage with a range of stakeholders in order to address complex social problems (Ozanne, Davis, Murray et al. 2017). As the Transformative 
Consumer Research (TCR) agenda grows, marketing academics increasingly focus on achieving societal impact through their work (Mick, 2006). In this context, Ozanne et al. (2017) make a timely call to researchers to forge relations that drive societally relevant research with the potential to improve and transform consumer lives, what they term 'relational engagement' (p2). Ozanne et al. (2017) document some of the ways that productive interactions between various stakeholders can be harnessed to bring greater mutual understanding of the social problem under study (e.g. DeBerrySpence, 2010; Wansink, 2012). This paper specifically builds on Ozanne et al.'s (2017) relational engagement perspective by exploring the barriers that impede both the initial stages of collaboration between marketing academics and Social Impact Organizations (SIOs) and the on-going development of these relationships. A key output of this paper is a set of recommendations for TCR researchers to support them to overcome these barriers. Our research questions are: What are the barriers that marketing academics face when seeking collaborations for societal impact? How can TCR researchers overcome these barriers to ensure that impactful relationships are created and sustained? Taking an abductive approach to this issue, we develop our understanding of the barriers through a process of iteration between the empirical observations and the relevant literature (Dubois \& Gadde, 2002).

Our findings reveal three significant challenges for marketing academic researchers who seek to initiate and maintain impactful relationships. These challenges were not raised by Ozanne et al. (2017), and we therefore aim to provide a useful and rigorous extension of that work. Ozanne et al. (2017) highlight the important capacity building benefits that flow from relational engagement. However, their focus on capacity building as a research outcome does not capture the initial, and subsequent, resource inputs needed from each party to realise this potential benefit. 
Nor does it address issues around the reciprocal value derived from the relationship vis-à-vis resources at the disposal of each party and their respective resource investment priorities. Differing perspectives on resource investments, therefore, is the first barrier identified from our research. The second barrier revealed by our research related to the goals driving the relationship. Goal misalignment between academics and practitioners has been seen to hinder relationship initiation and development in other contexts (Keiser \& Leiner, 2009; Stokols, Misra, Moser, Hall, \& Taylor, 2008) but remains to be explored in the context of social impact research. The third barrier identified in our research is that assumptions about the other party can underpin and undermine the relationship, and this phenomenon also remains under-researched. While scholars in social marketing, non-profit marketing and public policy have worked to transform business practices and knowledge on behalf of consumer wellbeing (Andreasen, 2002; Dibb \& Carrigan, 2013; Peattie \& Peattie, 2009; Sirgy \& Lee, 2008), perceptions of marketing as a potentially harmful for-profit practice remain.

We structure our paper as follows: first, we bring together relevant literature that explores the three barriers to relationship building that emerged from our data in order to set our findings in the context of current research. We then provide an overview of our method and analytical approach, followed by our findings relating to the key barriers to relational engagement. Finally, we discuss the implications of our findings for TCR researchers and marketing academics, providing recommendations for practices and processes that will allow researchers to overcome barriers and engender high quality relationships for societal impact. 


\section{Conceptual Background}

Stakeholder engagement has become an increasingly important focus of studies in marketing and business research (e.g. Corus \& Ozanne, 2012; Nenonen et al, 2017; Scandelius and Cohen, 2016). Such an emphasis represents an important complement to the impact measures (publications and citations) that have traditionally dominated academia. Key to this development is the relationships that researchers form with the stakeholders their research aims to serve - non-profit organizations, policy makers, social practitioners, activists, community members, consumers and service-users. In order to achieve impact in these spheres, Ozanne et al. (2017) encourage researchers to engage in "new forms of productive interaction with end users" (p.1), with a view to creating knowledge products in partnership with stakeholders, which are "more likely to affect positive social change" (p.2). This engagement with stakeholders represents an opportunity for fusing theory and practical knowledge (Kalb, 2006; Murray \& Ozanne, 1991; Ruiz \& Holmlund, 2017) to develop theory-guided action and conversely, practice-informed theory.

Encouraging this new orientation to stakeholder engagement, Ozanne et al. (2017) suggest the academic researcher becomes "“copreneur', advocate, cocreator and provocateur" (p.12). This language of co-production speaks to service-dominant marketing logic, placing emphasis on relationships and the network of stakeholders within which value is created (Lusch \& Vargo, 2014; Vargo \& Lusch, 2004; 2008). While collaboration and active co-creation are needed for the creation of shared value for all involved (Ind, Iglesias, \& Schultz, 2013), problems remain in the initiation and early development of these relationships. We identify three issues in our data: (1) differing resources and approaches to resource investment in research; (2) competing goals and goal alignment; and (3) diverse assumptions about the other party. These 
areas represent barriers to, and opportunities for, the development of academicstakeholder relations, not yet addressed in previous work in the TCR domain. Below, we draw on prior work from a range of disciplines to provide a contextual background and theoretical underpinnings to help understand these barriers.

Various authors have argued that collaborative organization-stakeholder relationships are based upon a reciprocal exchange of resources (tangible or intangible) to generate value for the relational partners (Finch, Varella, Foster, et al., 2016; Freeman, Wicks, \& Parmar, 2004; Lusch \& Vargo, 2014). However, a key challenge when defining values relates to the nature of the resources available to the various stakeholders and the competing and contradictory demands on these resources (Pettigrew, Cornuel, \& Hommel, 2014). In the context of academic-practitioner relations, resources include time, technical expertise, intellectual ideas, research methodologies, money, space and electronic infrastructure and institutional legitimacy (Amabile, Patterson, Mueller, et al., 2001; Finch et al., 2016; Stokols, et al., 2008). Differing resources and resource priorities may produce a number of outcomes. For example, mismatches in schedules between researchers and stakeholder organizations can form a type of "time incongruity" in which the time cultures and structures of one sector are ultimately unfamiliar and incompatible with the time cultures and structures of another (Kaufman, Lane, \& Lindquist 1991). In other cases, resource mismatches can be positive for relational engagement. For example, different knowledge bases and skills can complement project outcomes for practitioners and academics (Bartunek \& Rynes, 2014). This encourages the combining of practical and theoretical approaches and improves the capacity for group problem solving through greater breadth of perspective and greater creativity (Hambrick, Cho and Chen 1996). Thus, although differing resources in academic- 
practitioner relationships can provoke tensions, they can also enhance relationship performance if successfully harnessed.

In addition, there are questions around the goals underpinning the relationship. Stokols et al. (2008: S104) studied science collaborations and concluded that teams whose "members endorse competing goals and outcomes; hold different views of science and society; and use dissimilar terminology, language and decision-making styles are likely to experience conflicts that undermine the team's performance". While their focus was on transdisciplinary teams, the point remains that divergent worldviews and backgrounds can hinder the effectiveness of academics' relationships with stakeholders. A key issue facing academic-practitioner collaboration is the rigour-relevance debate (Bartunek, 2007; Keiser \& Leiner, 2009), with academics accused of over-scientifizing ideas at the expense of relevance for the real-world issues and problems faced by practitioners, and practitioners often dismissing the value of grounding a study in theory. Thus, goals around knowledge production underpin academic work, but compete with practitioner goals to find practical solutions to pressing hands-on problems.

In addition to thinking about the goals driving the relationship, the institutional goals in a wider social and political context can shape relational development and engagement. In the UK, the research impact of academic output is assessed by government using the Research Excellence Framework (REF), with a focus on impact as "an effect on, change or benefit" to wider society (HEFCE, 2016). With this emphasis on measurable real-world impact, academics are encouraged towards greater knowledge exchange (KE), leading to a greater emphasis on external relations with funders, users and other stakeholders (Chubb \& Reed, 2018). Increasingly, collaborating with external stakeholders is a reality, with academics in 
applied subjects more likely to be involved in knowledge exchange activities (Doberneck and Schweitzer, 2017). This greater focus on, and investment in, engagement (by universities and academics) can result in better external collaborations and expertise (Watermeyer \& Lewis, 2017), and thus have an extended benefit of enhancing stakeholder engagement longer term. Nonetheless, another rigour-relevance question remains. Chubb \& Read (2018) report on academics' concerns around the pressure to produce findings with relevance to practitioners alongside the more academic focus on making theoretical contributions to current debates, further highlighting the pressures of goal alignment with diverse stakeholders. This is a challenge for marketing and TCR researchers as they seek out these relationships, but also face pressure to publish papers in leading academic journals and to produce the type of research valued by universities.

TCR researchers will likely be familiar with the associations of the marketing discipline that abound in lay understandings - primarily that the discipline is simply a training ground for marketing practitioners. Mass media portrays marketers as people who do not engage in caring for consumers or indeed who exploit them (Cluley 2015) and other researchers have noted that "critics consequentially put most of the blame for societal problems on marketers' shoulders" (Stoeckl \& Luedicke, 2015 p.2460). This negative association can damage the legitimacy of marketing academics approaching social issues (Marion, 2004). Indeed, Mick himself (2006) embedded into the discourse that launched the TCR movement the criticism that marketing represents the darker side of business wherein the goal is to persuade consumers to buy, therefore exacerbating poverty, health problems and waste. However, the fact that the discipline is perceived as operational, with a particular set of tools for problem solving, rather than looking for "the pursuit of knowledge for its own sake" 
(Macfarlane, 1995 p.2), can indeed play in its favour when looking for partnerships with SIOs, the public sector or companies.

In summary, co-produced relational engagement between marketing academics and SIOs is critical for the pursuit of research that is likely to produce meaningful change and improvement to social problems (Ozanne et al, 2017), but the initiation and subsequent stages of these relationships are still under-studied and form the basis of this research.

\section{Method}

Given the exploratory nature of our research and our objective of understanding, rather than measuring, stakeholder relationships, we adopted a qualitative research design (Creswell, 2013). Data collection focused on interviews with two key stakeholder groups: Social Impact Organizations (SIOs), which are organizations (such as charities) working to address social problems and university employees who focus on knowledge exchange (KE). All members of the research team conducted interviews. The purpose was to identify anticipated or experienced barriers to forming and maintaining mutually beneficial relationships between marketing researchers and SIOs and, from this, to build a set of recommendations on how these barriers can be managed.

The first set of interviewees were individuals employed in Social Impact Organizations (SIO). SIOs have important roles as facilitators of transformation; they strive to resolve significant social problems through their links with communities and end users (Bublitz, Escalas, Peracchio, et al., 2016). Although working across a range of sectors, the mission of all of the organizations represented in our sample relates to transformative social impact (details in table 3.1). We created a semi-structured 
interview guide exploring perceptions of marketing research, experiences of collaboration including the instigation of collaborative relationships, successes and failures and project outputs. The interview guide allowed for flexibility based on the interviewee's position yet ensured continuity as we explored common themes.

We used non-probability purposive sampling to allow us to actively seek out key participants, drawn from personal networks and contacts. In order to reflect the international nature of marketing academia, and in particular TCR work, we collected perspectives and data from three countries, the UK, France and the US. All of our participants have had considerable experience of collaborating with academics, but the extent and nature of engagement varied. Table 3.1 provides a detailed overview of our SIO participants.

\section{Insert Table 3.1 about here}

Our second group of interviewees is university employees who focus on Knowledge Exchange (KE) across campuses and with the community at large. The nature and role of these employees differs across the three countries in which this research took place. In the UK, research-led universities employ a cadre of people who are academically qualified (often to $\mathrm{PhD}$. level), with titles including “Knowledge Exchange Manager”, "Community Engagement Director” and "Impact Officer." These individuals are positioned in the broad area of KE and work bidirectionally in a number of sectors with public and private organizations seeking university experts as well as with academics seeking to develop practical applications or data. While collaborative efforts abound in US universities, the term "Knowledge Exchange Manager" is not common; instead KEs may be known by titles such as 
"Coordinators of Outreach" or "Community Service Coordinators". They may also align with the national Campus Compact organization to facilitate public purposes through higher education. In France, universities and schools do not usually have individuals allocated to KE roles, rather they tend to have units focused on establishing bridges with various public and private organizations for funding research projects. Individuals working in all of these roles have been included in this research.

The KE interviewees had many years of experience in performing a bridging function across the academic/practice divide, not only with marketing or business school academics, but with researchers from a broad range of disciplines across large universities. Again, we developed a semi-structured interview guide to allow deep understanding of barriers to relational engagement and possible solutions. Our sample is drawn from appropriate KE professionals employed within our own institutions. Table 3.2 provides an overview of our KE participants.

\section{Insert Table 3.2 about here}

In total we conducted 20 interviews (12 SIO, $8 \mathrm{KE}$ professionals) from the US, UK and France, with interviews lasting from 45 to 80 minutes. All were transcribed for analysis purposes, with pseudonyms ascribed to participants. To anonymize SIOs and universities, we removed names and instead describe their mission and purpose. Data analysis was on-going throughout the project, with all coauthors following an abductive process of systematic combination as we iterated between the empirical data and the literature (Dubois \& Gadde, 2002). Our close reading of the transcripts allowed us to develop a set of open codes: (1) Resources; (2) 
Goals; and (3) Assumptions around academic/SIO collaborations. From these we undertook a comparative analysis across the entire data set (Miles and Huberman, 1994; Strauss \& Corbin, 1990).

\section{Findings}

To develop an understanding of how relationships between marketing academics and SIOs are initiated, forged, nurtured and, ultimately sustained, we consider the barriers and challenges that emerged from our data. Through this analysis we generate data-driven recommendations for TCR researchers for successful relational engagement.

\subsection{Differing Perspectives on Resources and Resource Investments}

Relational engagement requires resource investment from both parties. However, access, availability and amounts of specific resources can vary dramatically between academia and SIO partners. While resources can range from scientific expertise and funding through to information technology and urban spaces, in this section, we focus on the three resource tensions that are most prominent in our data: scheduling, time supply and skills/expertise.

Time emerged as a crucial resource from both sides of the relationship. Mismatches in schedules between academics and social practitioners can form a type of time incongruity (Kaufman, et al., 1991), thus representing a barrier to relationship development. Ian, who coordinates academic student projects with community nonprofit organizations, outlines these conflicting schedules:

The non-profit world and the university almost to the hour operate on conflicting schedules. Courses end within the fourth quarter of the annual year, which can be a time for 'donation desperation' for a non-profit. Schools 
are on a fiscal year schedule and there are no students in the summer. The year starts on January 1 for non-profits and on July 1 for universities. (Ian, SIO, US)

Such incongruity can create friction and missed opportunities. Particularly of concern is the time lags created by time incongruity. The lengthy funding application process is alien to SIOs who, as Jamie indicates, work in a more immediate way:

It can take forever it seems, you know, for bids to go through... We've had letters of support in the past expire, that time lag can be a real barrier and that can also not fit for us - if someone says we want to do something in a year and a half's time, we just say, well, come back then. (Jamie, SIO, UK)

While SIOs need immediate actionable solutions, academic projects often "take years to get off the ground" (Barbara, SIO, UK). For Barbara, this is incompatible with her role in supporting children living in poverty and her concern that immediate action is required - time is an unaffordable luxury. Although contrasting time frames may cause tension for all kinds of academic-practitioner collaborations, this resource tension takes on greater significance when working with pressing social problems.

Data reveals that time and money are interlinked and concerns regarding the resourcing of time were mentioned consistently across interviews. Crucially, SIOs indicate a 'time is money' perspective, concerned with the cost of time of setting up meetings, going through approvals and applying for funding:

Smaller enterprises or charities where the time of the CEO or a member of staff has to be costed for - the transactional value of that relationship has to be taken into account. (Tariq, SIO, UK)

Our data suggests that academics often assume that the SIO partner will contribute time freely. But SIO time must be recovered, as it is time spent away from other 
activities that are often core to the organization's remit. As Ian (SIO, US) suggests, time investment in collaborations leads to "a lot of unanswered calls and unanswered emails.... Is it worth the time it will take?" (Ian, SIO, US). SIOs embarking on relational engagement TCR projects are often resource-constrained and, hence, the return on time invested needs to be clear.

Intellectual capital and expertise represent another resource that is critical to relational engagement. Our SIO informants view academic expertise in various ways. Positively, there is clear recognition among informants of the ways academic expertise can enhance the work of SIOs:

(Working with academics) enables us to access the funding stream which we're not able to access on our own and, secondly, it would add a, kind of, extra dimension to the organisation, because we're never going to have the research capacity internally to do that kind of research. So we need to do it in partnership with somebody and we need the expertise and intellectual muscle and, sort of, heft that comes of working with an academic. (Jamie, SIO, UK) Experience and skills in compiling funding proposals and academic gravitas are seen as sources of value that complement the existing expertise of SIOs. Interestingly, the expertise of individual academics is seen to be more important for SIO practitioners than institutional legitimacy. As Jamie (SIO, UK) comments, "it's more about the person than it is the institution actually." Others share this view and suggest that their preference was to have good relationships with key individuals in order to continue the link when academics move to another institution. Those SIO participants with knowledge about TCR were enthusiastic, they viewed it as a research stream that contributes both the "intellectual muscle" that Jamie discusses above, and also engagement with lived experience. However, whilst SIO practitioners clearly value 
academic expertise, some of our informants believe this respect is not reciprocated. Many express frustration at academics who do not use SIO expertise or intellectual contribution and merely involve SIOs as gatekeepers to access participants or to facilitate dissemination of outputs. SIO practitioners want academic partners to value their specific skills, practical experience and wisdom throughout the whole research process:

[What works are] those type of relationships where you really bring expertise from both sides and it is a real exchange, rather than academics thinking they know best and just, "Here is my findings. Please implement it." (Anita, KE, $U K)$

Successful partnerships therefore appreciate ideas and expertise from both sides for the duration of the project.

\subsection{Competing Goals and Goal Alignment}

The most effective relationships between SIO practitioners and academics are those where mutual benefit is articulated clearly in the initial project design. Goal alignment is critical to the success of projects, requiring collaborative effort to design research that delivers value to both relationship partners. As one KE professional says, "partnerships with academics don't work if the practitioner part is an 'add on", (Edward, KE, US). Goal alignment comes from both sides, providing a learning experience for both the academic and the SIO. Achieving a clear statement of roles and intentions in the early stages of a relationship is not a quick or easy process. There was a view that relationships require nurturing to develop a shared logic and bonds of trust. The issue of trust can be an institutional problem, particularly if universities and business schools are viewed as reaping benefits from their 
communities and not giving back. Edward describes a policy shift in his University that has contributed to a vastly changed public image:

For the last seven years, the effort to help non-profits has been an intentional commitment to connect with the community in meaningful ways. This has gone a long way to years and years and years of mistrust. This is not the narrative anymore. (Edward, KE, USA).

The importance of clear communication of goals was highlighted by a number of informants. Clear statements of what the project entails (topics, expected outcomes and value to the SIO) are important at relationship initiation stages and should be clear throughout a project. While this is an important aspect of initial conversations, it is also an area where the relationship can struggle if the academic is not clear on the value of their work to the SIO.

There was an academic colleague that said that he once started an email with, "I'm really interested in dadadada..." and the response was, "I don't care what you're interested in. Why should I care?" (Anita, KE, UK)

Where the academic and stakeholder goals and purpose are aligned, then exchange of value occurs. However, goal misalignment tends to feature when there is an over-reliance on a traditional academic approach, that is, where the academic harvests data from the field or comes to the field expecting their recommendations to be actioned. Barbara reflects that the academics, rather than end users, have shaped most academic projects she has been involved in:

I can't think of a time when the young people have been part of designing the research or carrying out the research. They've usually been the recipients of it, the research subjects. (Barbara, SIO, UK) 
Even when the relationship is established, and common goals agreed, there could be differing expectations of, and value assigned to, outputs. Whereas practitioners value timely, action-oriented and practical outputs, for academics the main type of output is the scholarly academic article or book (Ozanne et al., 2017). SIO practitioners are keenly aware of the outputs they seek from collaboration. They want practical reports, training programmes, communications materials or measurement of efficacy/impact of their services:

What is the benefit that we are going to get back? For instance, we will participate for a monetary donation, or for a document or a how to relate to client or to prepare a synopsis of our programs. (Ian, SIO, US).

For the KE partners, the output can be in the form of enhanced capacity building, as evident through the development of enduring networks of relationships. These networks may have a wider value through affording opportunities for further relational engagement:

I think one that is really quite underrated is this kind of long-term relationship-building. I think that, you know, in REF terms we always think of you need a paper or you need a report, or you need something like that. But for me it's those kind of like softer outputs, so having a group of engaged people on the outside who are likely to respond to your requests in the future, or help you build on the research or create more of a body of research. I think that's really useful, but how successful that is I'm not always sure, because I think academics then kind of move onto the next project and then don't carry on those (Lisa KE, UK)

SIO practitioners recognize the significance of research outputs to their academic partners, but as might be expected, some were cautious when considering 
the value of such outputs. Here, one SIO practitioner considers the potential 'disconnect' between academics' agendas and the 'lived reality' of child poverty, which her organization tackles on a daily basis.

Thinking about how much research does lead to change and how much of it raises an issue that goes in a report and sits on the shelf. Sometimes it can have a revolutionary effect in terms of the impact that it has and drawing attention to a problem and pushing the policy agenda forward. But more often than not it doesn't and it just describes a problem without suggesting ways forward or how to solve the problem. (Barbara, SIO, UK)

Thus, successful collaborations need to produce outputs which serve the goals of all parties of the relationship - both the academic papers valued by academic institutions and lay materials that can be easily and widely disseminated by SIOs.

\subsection{Diverse Assumptions and Views about the Other Party}

Assumptions about the nature of marketing, coupled with a lack of awareness of the breadth of the marketing discipline, can reduce the legitimacy of the marketing scholar in the social change context. As Etienne notes, this lack of understanding of the nature of marketing scholarship means that marketing academics are not initially considered for social impact projects:

The feeling I have is that often when people who are non-expert in marketing, from the civil society, get interested in these questions, they will look at sociology... but they don't go to marketing. (Etienne, SIO, France)

The SIO practitioners and KE professionals we spoke to tend to share a traditional understanding of marketing scholarship, rooted in the language of business and commerce. When asked to describe their understanding of teaching and research within academic marketing departments, participants used words such as "strategy," 
“advertising," “marketing materials," "packaging," "the power of sales, " who buys what," "profit management," and the "science of consumer behavior". While understanding was accurate, it was limited to a business and sales focus, in essence a for-profit stance. Hence, the prevailing view is that marketing academia is focused on serving the needs of the marketing industry, teaching the practical skills for the role of marketer, with little or no engagement with consumer well-being or other issues of societal change that are relevant to TCR scholarship. As Mary (KE, UK) indicates the discipline may not be an obvious fit with social impact, "so in my head marketing is very close to selling or it's very consumption based. So in my head it doesn't fit overly naturally (with social impact)." The notion of discrete cultures assumes relevance here. Informants view the charity sector, and social impact research more widely, as a separate and distinct culture from that of marketing; one with differing ideologies and values. According to one KE informant, moving into the social change domain requires recognition that marketing academics are "stepping into a culture that is not your own" (Edward, KE, US). Others echoed this sentiment, indicating that an interest in business was antithetical to seeking societal improvement: "if I take a big cliché, it's the humanists against the business men" (Robert, SIO, France).

This perspective can impede the inception of relational engagement collaborations. Perceived ideological difference is particularly evident in discussions of the use of marketing terms and business language. For example, Edith contrasts the ideals-driven nature of charities with the business scholar's assumed interest in profit and 'the bottom line':

Terms such as 'researching a problem' are also barriers. Non-profits know that they are there to solve problems. A business perspective on solving 
problems might be to focus only on the bottom line. Non-profits already solve problems. (Edith, SIO, US)

For this informant the language of marketing research serves to undermine the SIO, and she contrasts the rational, business approach, 'the bottom line' to that of the problem-solving SIO.

However, informants did recognise and acknowledge the limitations of this assumption. As SIOs and KE professionals start to interact with and develop relationships with marketing academics, their preconceptions fade, and they begin to reframe marketing in potentially positive terms. For example, Barbara describes her first impressions following attendance at a seminar:

It was really surprising because it looked at issues that I didn't think a marketing department would. There were some quite exciting pieces of research that were presented and a lot of it was about the lived experience of people, which was really encouraging. Sometimes it does feel like there's a gulf, a disconnect from that lived reality and very few researchers that I've come across really thoroughly engage with those with the lived experiences. (Barbara, SIO, UK)

TCR's emphasis on societal impact appeals to SIOs with its blend of intellectual theorizing and real-world application. Further, as Anita outlines, misunderstandings of marketing can be overturned through collaborative projects:

I think when I started initially I was surprised at the idea of a marketing academic just because that's ignorance on my part. I come from a university where there wasn't a business school, so I was thinking, "is that a discipline?" I think Catrina (marketing academic) was probably the first... 
and then I realized this is proper academic work. There's a lot to it. (Anita, $K E, U K)$

Although the skillset and research focus particular to marketing is not always obvious, there is recognition of the particular value marketing academics bring to social impact work. Several SIO practitioners deemed the use of marketing language, such as the label 'consumer', helpful, albeit in two quite different ways. First, this language enables the application of the tools of marketing (e.g. segmentation, marketing communications, consumer insight and advertising) to the perennial problems nonprofit organizations face - reaching end-users and fundraising. Anita encapsulates the value of a marketing approach to social problems:

In a way, if you're teaching that practice to charities and social enterprises as well so that they can compete with the big brands...well, not compete, but they get through the noise, I think that's important too. (Anita, KE, UK)

Second, and perhaps more interesting for the TCR movement, the use of the term 'consumer' was viewed positively. Barbara (SIO, UK) finds the term helpful as it acknowledges that we are living in a damaging consumer society and that this is the context against which many SIOs, including her own, work: "that's the narrative that we're presented with and that's what we're up against." Hence, for several informants the language used by marketing researchers and the marketing toolbox itself, are an asset, facilitating a critical depiction of the modern-day context in which their clients live and offering a set of tools to enact change.

\section{Discussion and Recommendations}

Research with societal impact is a central aspiration of the TCR movement. Ozanne and Davis (2017) described the importance of relational engagement between key stakeholders, emphasizing the importance of connectivity and teamwork with a 
shared vision, strategy and goals underpinning research for societal change. The objective of our research is to use an empirical investigation to develop new understanding of key barriers that impede the forging of impactful, sustained relationships between marketing academics/TCR researchers and social impact organizations. In line with this objective, we have identified three key barriers to relational engagement, relating to: (1) differing perspectives on resources and resource investments; (2) competing goals and goal alignment; and (3) diverse assumptions about the other party. Drawing on our analysis, we have developed a series of specific recommendations. These recommendations are data-driven, emerged from our conversations with informants, and we provide illustrative exemplars from data and examples drawn from our wider networks too.

While many successful academic-SIO relationships are organic and personally initiated, it became clear that the aforementioned barriers can hinder marketing academic-KE relationships. In particular the assumptions KEs have about academic marketing research, leaving less scope for marketing scholars pursuing socially impactful research. We summarize our recommendations in Table 5.1 and offer some illustrative examples to inspire action. Our recommendations are primarily aimed at marketing academics and TCR researchers, yet we suggest that the responsibility for relationship building does not rest solely with the academic partner. Rather, we draw attention to opportunities that academics may find useful as they seek out and develop collaborations.

\section{Insert Table 5.1 about here}




\subsection{Differing perspectives on resources and resource investments}

The main barriers linked to resources emerged in relation to skills/expertise, scheduling and time supply. In terms of managing the resource base linked to skills and expertise, Kazadi, Lievens, \& Mahr (2016) stress the importance of mapping competences and capabilities early in the process of working with multiple stakeholders. And yet, our findings show that the time investment associated with the development of relationships can be a barrier to relational engagement. This often informs the nature of the collaboration. SIOs turn to partners/relationships already in place, to minimise time and costs associated with developing new relations. By implication, early career academics or those without established partnerships may struggle in forging relationships. This is where input from dedicated professional KE staff becomes significant. KE professionals can offer what Lunt, Fouché, \& Yates (2008, p.50) refer to as a "framework of opportunity" by promoting partnerships through the provision of appropriate support that encourages both parties to reflect on their resources and optimize their skills. In this way, we build on Kazadi et al. (2016), and our first recommendation for enhancing societal impact is to maximize the resources and framework of opportunity provided by KE Professionals

(Recommendation 1). Often, academics perceive these KE professional services staff as most useful for the dissemination of research findings. However, we encourage marketing academics to seek support from KE staff in relation to: (1) instigating collaborations, (2) organizational and logistical support, (3) managing expectations. First, it is clear that KE staff are useful gatekeepers and have access to wider networks - there is therefore an opportunity for KE professionals to work with academics and SIOs to produce a networked academic-SIO unit, which can have a wide-ranging and enduring benefit for many academics and SIOs. Second, KE 
professionals can provide important organizational and logistical support, which can free up academic time for deeper engagement with the SIO partner. Third, involving KE professionals in the early stages of relationship building can support the management of expectations. For example, KE professionals can alert SIOs to scheduling issues so there is greater understanding of how the relationship will work in practice. This issue of expectation management is discussed by a number of KE professionals and informs Recommendation 2, which focuses on valuing the expertise of both parties and identifying carriers of impact. This step towards cocreation will ensure that the relationship is sustainable.

Similar to other work on academic time (Kaufman, et al., 1991; Ylijoki \& Mantyla, 2003), time incongruity can create friction, missed opportunities and anticipated conflict when both "sides" do not attempt to develop a joint schedule compatible with everyone. In relation to the time incongruity associated with conflicting schedules, we recommend creating structures for blocking dedicated time for collaborative work (Recommendation 3). This may take the form of intensive workshops, or regularly scheduled resource meetings that can help all partners to allocate their resources while building understanding of similarities and differences among them. For instance, a moderator-led discussion of a central topic may lead to the sharing of relevant methodologies that can be utilized in addressing the goals of a specific investigation. Further, the assurance of an on-going relationship can mitigate the somewhat unpredictable nature of academic schedules so that SIO activities can continue without interruption. 


\subsection{Competing goals and goal alignment}

Initializing and building connections characterize the early stages of relational engagement. Spending time together to establish common ground between stakeholders is important in terms of mitigating goal misalignment (Kazadi et al., 2016; Stokols, et al., 2008; Watermeyer \& Lewis, 2017). A key issue in terms of goal alignment relates to the outputs associated with the research and the extent to which both parties appreciate the outcomes expected by the other (Chubb \& Read, 2018).

Given that engagement is foundational to the TCR agenda, this is particularly important for marketing academics working on societal impact projects, and forms the basis of Recommendation 4, which recommends the co-production of the academicSIO relationship to ensure alignment of goals.

Building on the development of shared goals and vision for developing microlevel connections, there is an opportunity for a move towards a more structured approach to the management of academic-SIO relations within wider settings of universities and organizations. In terms of developing and nurturing on-going relations between the academics and SIOs, it is useful to consider the differing value placed on the collaboration outputs by the different stakeholders. While academics have traditionally valued the academic scholarly article or book as the main output from research, this is shifting with the move towards the engaged researcher (Doberneck and Schweitzer, 2017). With this in mind, there is an opportunity for SIOs and academics to think more creatively about what value is in context, how it will manifest itself for the different partners and how this can be expanded upon to bring a wider more co-creative approach to the output from the work. There may be opportunities for collaboration on different types of outputs, with each partner getting something they need within their own organization while simultaneously shaping 
each other's traditional outputs. Structured events may be useful here, along the lines of Sandpit (Corbyn, 2009) and Collider research events.

Interviewees gave examples of events organized, with the purpose of facilitating connections between potential collaborators (SIOs and academics) through exploring thinking around vision, purpose and goals. KEs and SIOs often hold events to promote academic collaborations, these offer an opportunity for researchers to share their research agenda, build networks and develop relationships. Such events form the basis of Recommendations 5 and 6, namely the recommendation for KEand SIO-led events to explore common interests, goals, vision between stakeholders. KE-led initiatives tend to be focused on bridging activities to widen networks, leading to enhanced stakeholder networks, such as the Policy@ Manchester initiative (see table 5.1). SIO-led initiatives, in contrast, may be focused on specific societal problems, possibly aligned to particular funding streams. Events and meetings designed to offer 'organic' networking with SIOs offer space to find common interests, build trust and break down assumptions. These networks may have the additional benefit of enhancing understanding of different organizational cultural perspectives, central to effective partnerships for relational engagement. There can be specific events aimed at different career experience/levels.

\subsection{Diverse assumptions and views about the other party}

Negative assumptions about marketing and misunderstandings of the marketing discipline emerged as a barrier to relational engagement. Marketing is associated with waste and excessive consumption, the destruction of resources and social inequalities (Hackley, 2009), which contributes to negative stereotypes of marketers (Cluley 2015) and can damage the legitimacy of marketing academics 
approaching social issues. The dissonance between the poor public image of marketing (Cluley, 2015) and the societally enriching work of marketing and TCR scholars should not be underestimated. However, we found that these assumptions were overturned through collaboration and interaction with marketing and TCR academics. This represents an important opportunity for enhancing the legitimacy of marketing for societal impact (Marion, 2004) and forms the basis of a number of recommendations.

Our recommendations in this regard relate to engaging in activities to promote the role of marketing in societally important research and thereby contribute to the dismantling of some of these assumptions. This is important, as assumptions can be magnified into barriers if sufficient opportunities for conversation do not exist. As an example, a complex picture emerges about the practice of "profit-based" marketing, which can create initial psychological barriers with SIOs. We found negative assumptions about marketers mixed with more positive interest in "social marketing," “consumer marketing," and "public policy marketing." Such qualifiers can help to counterbalance assumptions about profit motives, allowing SIOs to recognize value in the consumer lens and marketing toolbox generally. The implications of these assumptions are that marketing scholars may initially face barriers to working with SIOs based on the lack of perceived fit in this realm. An important stage in challenging these assumptions is our role and activities with the next generation of marketers. This leads to our recommendation encouraging the use of teaching activities as a springboard for developing collaboration (Recommendation 7). The organization of guest lectures and student projects has significant pedagogic benefits and can also kickstart conversations that lead to sustained collaborations. We also highlight the opportunities in raising the online visibility of our research to reach new 
audiences, both within and outside of academia (Recommendation 8). Ozanne et al. (2017) have recommended marketing researchers to be more active on various types of social media to become public figures of social change/impact. In developing an online presence, networks such as LinkedIn can serve a useful purpose in reaching a wide audience and directing followers to blogs and personal webpages. Another means of promoting our research could be through searchable databases of researchers (Recommendation 9), where researchers indicate their research interests, their vision and the organizations they would ideally like to work with. Such databases could be accessible to everyone, so SIOs could develop a different perspective on marketing's potential to create social impact.

In summary, researchers working on TCR projects need to reconcile different institutional and SIO demands in order to work towards developing lasting mutually beneficial research teams (Davis, Ozanne \& Hill, 2016) and societal impacts that their institutions and funding bodies will recognize and support. Our findings remind us that as academics we do not have the monopoly on wisdom. We advocate a holistic approach to implementing the recommendations above in the efforts to overcome the barriers. While the implementation of these recommendations may be resource intensive (for example participation in KE- and SIO-led workshops), it is our view that this focused investment is rewarded with reduced barriers, stronger research networks, research projects which create change and strong relational engagement collaborations. The recommendations operate as an alert to the TCR researcher about the possibly overlooked resources that could assist in their TCR research agenda.

\section{Conclusion}

While social impact beyond academia is increasingly encouraged and recognized, there exist a variety of interpretations as to what constitutes impact (e.g. 
Ozanne et al., 2017). TCR researchers should not underestimate the challenges inherent in forming and sustaining relationships with SIOs but we hope that our paper has shown how we can begin to dismantle barriers and form high quality relationships for social impact. Importantly, we use data from this investigation to offer concrete recommendations for marketing academics and TCR researchers that they can implement in their research practices and wider institution. We do so to encourage a widespread sharing of best practice to engender the relationships which offer value and tangible outputs to both relationship partners. In terms of future research, it would be enlightening to consider the challenges and issues faced by marketing academics and TCR researchers as they work with a broader network for societal impact, including relations in transdisciplinary contexts and for-profit organizations.

\section{References}

Amabile, T. M., Patterson, C., Mueller, J., Wojcik, T., Odomirok, P. W., Marsh, M., \& Kramer, S. J. (2001). Academic-practitioner collaboration in management research: A case of cross-profession collaboration. Academy of Management Journal, 44(2), 418-431.

Andreasen, A. R. (2002). Marketing social marketing in the social change marketplace. Journal of Public Policy \& Marketing, 21(1), 3-13.

Bartunek, J. M. (2007). Academic-practitioner collaboration need not require joint or relevant research: Toward a relational scholarship of integration. Academy of Management Journal, 50, 1323-1332.

Bartunek, J. M., \& Rynes, S. L. (2014). Academics and practitioners are alike and unlike: The paradoxes of academic-practitioner relationships. 
Bublitz, M.G., Escalas, J.E., Peracchio, L.A., Furchheim, P., Grau, S.L., Hamby, A., Kay, M. J., Mulder, M. R. \& Scott, A. (2016). Transformative Stories: A Framework for Crafting Stories for Social Impact Organizations. Journal of Public Policy \& Marketing, 35 (2), 237-248.

Chubb, J. and Reed, M.S. (2018). The politics of research impact: academic perceptions of the implications for research funding, motivation and quality. British Politics, pp.1-17.

Cluley, R. (2015). The depiction of marketing and marketers in the news media. European Journal of Marketing. 50(5/6), 752-769.

Corbyn, Z. (2009). 'Sandpits' bring out the worst in 'infantilised' researchers. Times Higher Education, July $2^{\text {nd }} 2009$, down loaded from https://www.timeshighereducation.com/news/sandpits-bring-out-worst-ininfantilised-researchers/407201.article 18/11/1

Corus, C., \& Ozanne, J. L. (2012). Stakeholder engagement: Building participatory and deliberative spaces in subsistence markets. Journal of Business Research, 65(12), 1728-1735.

Creswell, J.W. (2013). Research design: Qualitative, quantitative, and mixed methods approaches. Sage publications.

Davis, B., Ozanne, J.L. and Hill, R.P. (2016). The Transformative Consumer Research Movement, Journal of Public Policy \& Marketing, 35(2), 159-169.

DeBerry-Spence, B. (2010). Making Theory and Practice in Subsistence Markets: An Analytic Autoethnography of MASAZI in Accra, Ghana. Journal of Business Research, 63 (6), 608-16. 
Dibb, S., \& Carrigan, M. (2013). Social marketing transformed Kotler, Polonsky and Hastings reflect on social marketing in a period of social change. European Journal of Marketing, 47(9), 1376-1398.

Doberneck, D.M. and Schweitzer, J.H. (2017). Disciplinary Variations in Publicly Engaged Scholarship: An Analysis Using the Biglan Classification of Academic Disciplines. Journal of Higher Education Outreach and Engagement, 21(1), pp.78-103.

Dubois, A. and Gadde, L.E. (2002). Systematic combining: an abductive approach to case research. Journal of Business Research. 55(7), 553-560.

Finch, D. J., Varella, P., Foster, W., Sundararajan, B., Bates, K., Nadeau, J., O’Reilly, N. \& Deephouse, D. L. (2016). The business school scorecard: Examining the systematic sources of business school value. Canadian Journal of Administrative Sciences/Revue Canadienne des Sciences de l'Administration, 33(4), 277-289.

Freeman, R. E., Wicks, A. C., \& Parmar, B. (2004). Stakeholder theory and "the corporate objective revisited". Organization Science. 15(3), 364-369.

Hackley, C. (2009). Marketing: A critical introduction. Sage.

Hambrick, D., Cho, T., \& Chen, M. -J. (1996). The influence of top management team heterogeneity on firms' competitive moves. Administrative Science Quarterly. 41(4), 659-684.

HEFC (2016). REF impact policy guide, downloaded from http://www.hefce.ac.uk/rsrch/REFimpact/ 17/11/17

Ind, Nicholas, Oriol Iglesias, and Majken Schultz. (2013). Building brands together: Emergence and outcomes of co-creation. California Management Review 55, no. 3 (2013): 5-26. 
Kalb, D. (2006). Uses of local knowledge. In The Oxford handbook of contextual political analysis.

Kaufman, C. F., Lane, P. M., \& Lindquist, J. D. (1991). Time congruity in the organization: A proposed quality-of-life framework. Journal of Business and Psychology, 6(1), 79-106.

Kazadi, K., Lievens, A. \& Mahr, D. (2016). Stakeholder co-creation during the innovation process: Identifying capabilities for knowledge creation among multiple stakeholders. Journal of Business Research 69, no. 2 (2016): 525540.

Keiser, A., Leiner, L. (2009). Why the Rigour-Relevance Gap in Management Research Is Unbridgeable. Journal of Management Studies 46(3): 516-33.

Lunt, N., Fouché, C. B., \& Yates, D. (2008). Growing research in practice (GRIP): An innovative partnership model. Families Commission.

Lusch, R. F., \& Vargo, S. L. (2014). The service-dominant logic of marketing: Dialog, debate, and directions. Routledge.

Macfarlane, B. (1995). Business and management studies in higher education: the challenge of academic legitimacy. International Journal of Educational Management, 9(5), 4-9.

Marion, G. (2004). Idéologie marketing. Paris: Eyrolles.

Mick, D.G. (2006). Meaning and mattering through Transformative Consumer Research. In Pechmann C. and Price L. (eds) NA-Advances in Consumer Research, 33, Duluth, MN: Association for Consumer Research, 1-4.

Miles, M.B., \& Huberman, A.M. (1994). Qualitative data analysis: An expanded sourcebook. (2nd ed). Sage; Thousand Oaks, CA. 
Murray, J. B., \& Ozanne, J. L. (1991). The critical imagination: Emancipatory interests in consumer research. Journal of Consumer Research, 18(2), 129-144

Nenonen, S., Brodie, R. J., Storbacka, K., \& Peters, L. D. (2017). Theorizing with managers: how to achieve both academic rigor and practical relevance?. European Journal of Marketing, 51(7/8), 1130-1152.

Ozanne, J. \& Davis, B. (2017) Making Research in Business Have More Impact: A Relational Engagement Approach AMA Scholarly Insights https://www.ama.org/academics/Pages/making-research-in-business-havemore-impact.aspx (accessed 3.5.2018)

Ozanne, J.L., Davis, B., Murray, J.B., Grier, S., Benmecheddal, A., Downey, H., Ekpo, A.E., Garnier, M., Hietanen, J., Le Gall-Ely, M., Seregina, A., Thomas, K.D. \& Veer, E. (2017). Assessing the societal impact of research: The relational engagement approach, Journal of Public Policy \& Marketing, 36 (1), 1-14.

Peattie, K., \& Peattie, S. (2009). Social marketing: A pathway to consumption reduction?. Journal of Business Research, 62(2), 260-268.

Pettigrew, A. M., Cornuel, E., \& Hommel, U. (Eds.). (2014). The institutional development of business schools. OUP: Oxford.

Ruiz, C.D. and Holmlund, M., (2017). Actionable marketing knowledge: A close reading of representation, knowledge and action in market research. Industrial Marketing Management, 66, pp.172-180.

Scandelius, C., \& Cohen, G. (2016). Achieving collaboration with diverse stakeholders - The role of strategic ambiguity in CSR communication. Journal of Business Research, 69(9), 3487-3499. 
Sirgy, M. J., \& Lee, D. J. (2008). Well-being marketing: An ethical business philosophy for consumer goods firms. Journal of Business Ethics, 77(4), 377403.

Stoeckl, V. E., \& Luedicke, M. K. (2015). Doing well while doing good? An integrative review of marketing criticism and response. Journal of Business Research, 68(12), 2452-2463.

Stokols, D., Misra, S., Moser, R. P., Hall, K. L., \& Taylor, B. K. (2008). The ecology of team science: understanding contextual influences on transdisciplinary collaboration. American journal of preventive medicine, 35(2), S96-S115.

Strauss, A., \& Corbin, J. (1990). Basics of qualitative research: Grounded theory procedures and techniques. Newbury Park, CA: Sage.

Vargo, S. L., \& Lusch, R. F. (2004). Evolving to a new dominant logic for marketing. Journal of marketing, 68(1), 1-17.

Vargo, S. L., \& Lusch, R. F. (2008). Service-dominant logic: continuing the evolution. Journal of the Academy of marketing Science, 36(1), 1-10.

Wansink, B. (2012). Activism research: Designing transformative lab and field studies. In Transformative consumer research for personal and collective well-being (pp. 95-116). Routledge

Watermeyer, R., \& Lewis, J. (2017). Institutionalizing public engagement through research in UK universities: perceptions, predictions and paradoxes concerning the state of the art. Studies in Higher Education, 1-13.

Ylijoki, O. H., \& Mäntylä, H. (2003). Conflicting time perspectives in academic work. Time \& Society, 12(1), 55-78. 